\title{
Toxicity of a cyanobacterial extract containing microcystins to mouse lungs
}

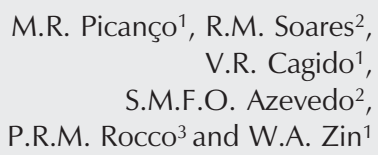

\author{
Laboratórios de ${ }^{1}$ Fisiologia da Respiração, \\ ${ }^{2}$ Ecofisiologia e Toxicologia da Cianobacteria, and \\ ${ }^{3}$ Investigação Pulmonar, Instituto de Biofísica Carlos Chagas Filho, \\ Universidade Federal do Rio de Janeiro, Rio de Janeiro, RJ, Brasil
}

\begin{abstract}
Correspondence

W.A. Zin

Laboratório de Fisiologia da

Respiração

Instituto de Biofísica, UFRJ

21949-900 Rio de Janeiro, RJ

Brasil

Fax: +55-21-2564-1578

E-mail: wazin@biof.ufrj.br

Research supported by PRONEX-MCT, CNPq, FINEP, and FAPERJ.

Received November 10, 2003

Accepted May 6, 2004

Toxic cyanobacteria in drinking water supplies can cause serious public health problems. In the present study we analyzed the time course of changes in lung histology in young and adult male Swiss mice injected intraperitoneally $(i p)$ with a cyanobacterial extract containing the hepatotoxic microcystins. Microcystins are cyclical heptapeptides quantified by ELISA method. Ninety mice were divided into two groups. Group $\mathrm{C}$ received an injection of saline $(300 \mu 1, i p)$ and group Ci received a sublethal dose of microcystins $(48.2 \mu \mathrm{g} / \mathrm{kg}$, ip). Mice of the Ci group were further divided into young ( 4 weeks old) and adult (12 weeks old) animals. At 2 and $8 \mathrm{~h}$ and at 1,2,3, and 4 days after the injection of the toxic cyanobacterial extract, the mice were anesthetized and the trachea was occluded at end-expiration. The lungs were removed en bloc, fixed, sectioned, and stained with hematoxylin-eosin. The percentage of the area of alveolar collapse and the number of polymorphonuclear (PMN) and mononuclear cell infiltrations were determined by point counting. Alveolar collapse increased from $\mathrm{C}$ to all $\mathrm{Ci}$ groups (123 to $262 \%$ ) independently of time, reaching a maximum value earlier in young than in adult animals. The amount of PMN cells increased with time of the lesion (52 to 161\%). The inflammatory response also reached the highest level earlier in young than in adult mice. After 2 days, PMN levels remained unchanged in adult mice, while in young mice the maximum number was observed at day 1 and was similar at days 2, 3, and 4 . We conclude that the toxins and/or other cyanobacterial compounds probably exert these effects by reaching the lung through the blood stream after ip injection.
\end{abstract}

Key words

- Microcystins

- Lung

- Inflammation

- Alveolar collapse
Toxic cyanobacteria in drinking water supplies have raised public health concerns in many countries due to the frequent occurrence of cyanotoxins produced by these microorganisms. Microcystins are the cyanotoxins most commonly found in these blooms (1). These toxins are cyclic heptapeptides that present more than 60 variables, generally differing in the nature of their two Lamino acids (2). The liver is the target organ where these molecules inhibit serine/threonine protein phosphatases, especially PP1 and PP2A, in the hepatocytes. This enzymatic inhibition causes morphologic dam- 
age to the tissue, which may lead to death or, in a chronic intoxication, may promote hepatic tumors (3). Microcystins in the liver can also induce hepatocytes to produce arachidonic acid metabolites such as prostacyclin $\left(6-\right.$ Keto $\left.F_{1} \alpha\right)$ and thromboxane $\left(\mathrm{TXB}_{2}\right)$ by stimulation of the cyclooxygenase pathway (4). This observation suggests that microcystins can promote inflammation, which may contribute to the hepatic shock that leads to death.

There are some reports from different regions of the world of human intoxication due to toxic cyanobacteria ingestion $(5,6)$. In Brazil, more than 100 chronic renal patients were intoxicated in the town of Caruaru in 1996 and 52 died due to intravenous exposure to water containing microcystins during dialysis treatment (7-9).

In addition to the oral and intravenous routes of intoxication, human beings can be exposed to cyanotoxins through inhalation. This may occur in recreational water containing cyanobacteria or their toxins. Fitzgeorge et al. (10) observed extensive necrosis of the epithelium of both olfactory and respiratory zones in mice that received a purified microcystin-LR (MCYST-LR) by the intranasal route. Through this route, the $\mathrm{LD}_{50}$ of this toxin was the same as that observed after administration by the intraperitoneal (ip) route. These investigators suggested that the phenomenon results from the necrosis of the nasal epithelium, which facilitates the absorption of the toxin into the blood stream through the nasal capillaries.

However, there are few reports analyzing the effects of microcystins on the lungs. Turner et al. (11) reported a case of two recruits in England who developed severe pneumonia after contact with water containing toxic Microcystis aeruginosa, and Slatkin et al. (12) detected pulmonary thrombosis in mice injected with lethal doses of microcystins. It has been already demonstrated that this toxin can reach the lung, and its distribution after oral and intratracheal administra- tions has been well described by Ito et al. $(13,14)$.

The aim of the present study was to analyze the time course of changes in lung histology in young and adult mice injected $i p$ with a cyanobacterial extract containing microcystins.

A toxic $M$. aeruginosa strain (NPJB-1) was cultured in ASM-1 medium as described by Ferrão-Filho and Azevedo (15). The culture was not axenic, but the concentration of bacteria was considered to be very low. At the exponential growth phase (between 15 and 20 days) the cells were harvested, concentrated with a Pellicon Cassette System (Millipore, Billerica, MA, USA) that uses a tangential flow multiple filter technique, resuspended in deionized water, and disrupted by cycles of freeze-thawing. Particulate organic matter was removed from the solution by filtration through fiberglass filters and the extract containing dissolved microcystins was used in the experiments. This strain has already been described as a producer of two types of microcystins: MCYST-LR and MCYST-LF (16). For this study, the total microcystins present in the strain extract were quantified by ELISA using the Envirologix Inc. (Portland, ME, USA) commercial plate kits, according to the manufacturer's protocol.

Ninety male Swiss mice were divided into two groups. The control group $(\mathrm{C}, \mathrm{N}=$ 30 adult animals) received an ip injection of $0.9 \% \mathrm{NaCl}(300 \mu \mathrm{l})$ and the test group (Ci) received an ip injection of a sublethal dose of cyanobacterial extract containing microcystins $(48.2 \mu \mathrm{g} / \mathrm{kg}$ body weight). The animals of the test group were equally divided into two groups according to age, i.e., young (4 weeks old) and adult (12 weeks old). At 2 and $8 \mathrm{~h}$ and at 1,2,3, and 4 days after the ip injection of the toxic cyanobacterial extract, five animals from the control and test groups were anesthetized with sevoflurane (2 minimal alveolar concentration), the trachea was occluded at the end of expiration and the 
lungs were removed en bloc.

The right lung was quick-frozen by immersion in liquid nitrogen and fixed with Carnoy's solution (ethanol:chloroform:acetic acid, $70: 20: 10)$ at $-70^{\circ} \mathrm{C}$ for $24 \mathrm{~h}(17)$. The Carnoy's solution was replaced with progressively increasing ethanol concentrations at $-20^{\circ} \mathrm{C}$ up to $100 \%$ ethanol. The tissue was maintained at $-20^{\circ} \mathrm{C}$ for $4 \mathrm{~h}$, warmed to $4^{\circ} \mathrm{C}$ for $12 \mathrm{~h}$, and then allowed to reach and remain at room temperature for $2 \mathrm{~h}$. After fixation, the tissue was embedded in paraffin, blocks were cut into $4-\mu \mathrm{m}$ thick sections with a microtome and the slices were stained with hematoxylin-eosin. Each slide received a code and two investigators who were unaware of the origin of the material performed microscopic examination.

Morphometric analysis was performed using an integrating eyepiece and a 100point grid consisting of 50 lines of known length coupled to a conventional light microscope (Axioplan, Zeiss, Oberkochen, Germany) (18). The fraction of the area of collapsed alveoli was determined by the point-counting technique at $200 \mathrm{X}$ magnification across 10 random non-coincident microscopic fields. Points falling on collapsed alveolar spaces were counted and divided by the total number of points in each microscopic field. Polymorphonuclear (PMN) and mononuclear cells and pulmonary tissue were evaluated at $1000 \mathrm{X}$ magnification. Points falling on the tissue area were counted and divided by the total number of points in each microscopic field. Thus, data were reported as the fractional area of pulmonary tissue. The same method was applied to determine the amount of PMN cells. All morphometric parameters determined for all groups were compared by one-way ANOVA and the level of significance was set at 5\% in all analyses. Statistical analyses were performed using the SigmaStat software (Jandel Scientific, San Rafael, CA, USA).

The percentages of alveolar collapse and PMN cells are illustrated in Figure 1. The fraction of alveolar collapse was higher in all test groups compared to control, independently of the time of analysis, reaching a maximum value earlier in young than in adult animals. The amount of PMN cells increased with the temporal evolution of the lesion. It is interesting to observe that in young mice the inflammatory response also reached its highest level earlier than in adult animals. After two days, PMN levels remained unchanged in adult mice, while in young mice the maximum level was observed at day 1 and was similar at days 2, 3 and 4 (Figure 2). Additionally, young animals responded with an earlier increase of PMN, followed by collapse whereas adult mice exhibited an inverse profile. These differences could probably be attributed to discrepancies in inflammatory mechanisms, i.e., in young mice, together with PMN infiltration, type II pneumocytes may also be altered very early in the course of lung injury, leading to surfactant dysfunction and alveo-

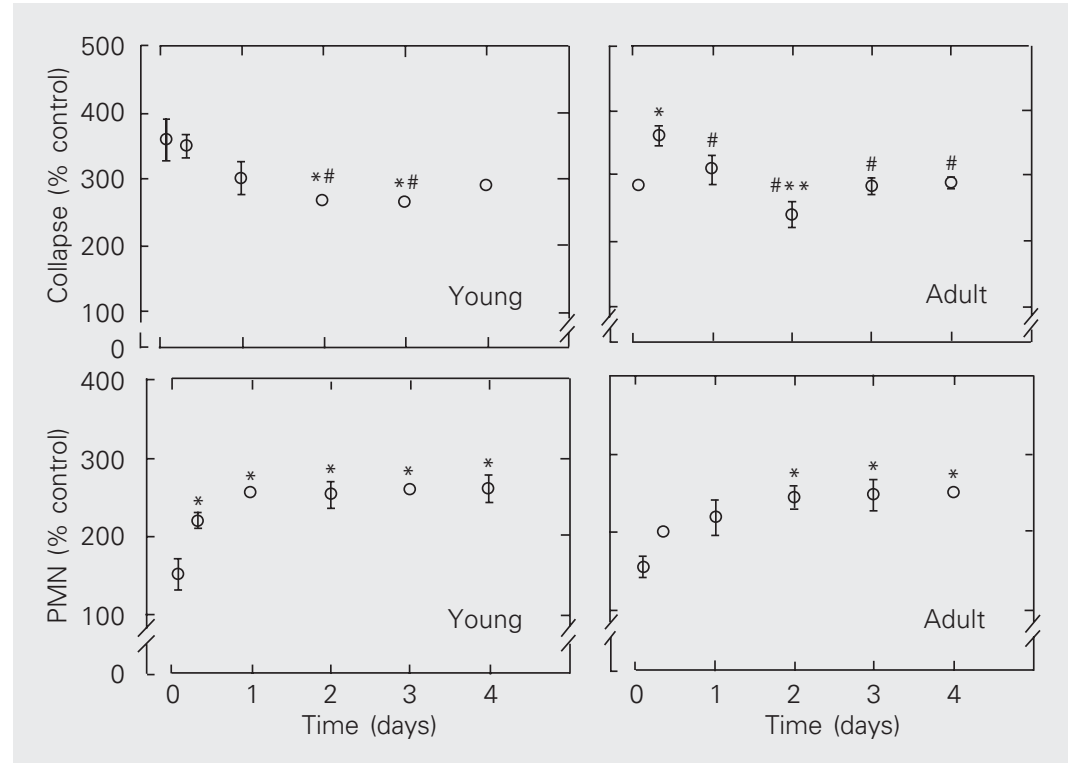

Figure 1. Effect of a cyanobacterial extract on the fractional area of alveolar collapse and the amount of polymorphonuclear (PMN) cells compared to the control group. The left panels provide the data for the young mice who received a sublethal dose of cyanobacterial extract containing microcystins $(48.2 \mu \mathrm{g} / \mathrm{kg}, \mathrm{ip})$. The right panels contain the data for adult mice who received the same dose. Data are reported as means \pm SEM for 5 lungs in each group (10 random non-coincident microscopic fields were analyzed in each lung). ${ }^{*} \mathrm{P}$ $<0.05$ compared to the 2-h period; ${ }^{P} P<0.05$ compared to the 8 -h period; ${ }^{*} \mathrm{P}<0.05$ compared to the 24-h period (one-way ANOVA). 
lar collapse, while in adult mice alveolar collapse peaked at $8 \mathrm{~h}$.

Therefore, we observed that the M. aeruginosa extract containing microcystins generated a rapid inflammatory process in mouse lungs, with interstitial edema and recruit-
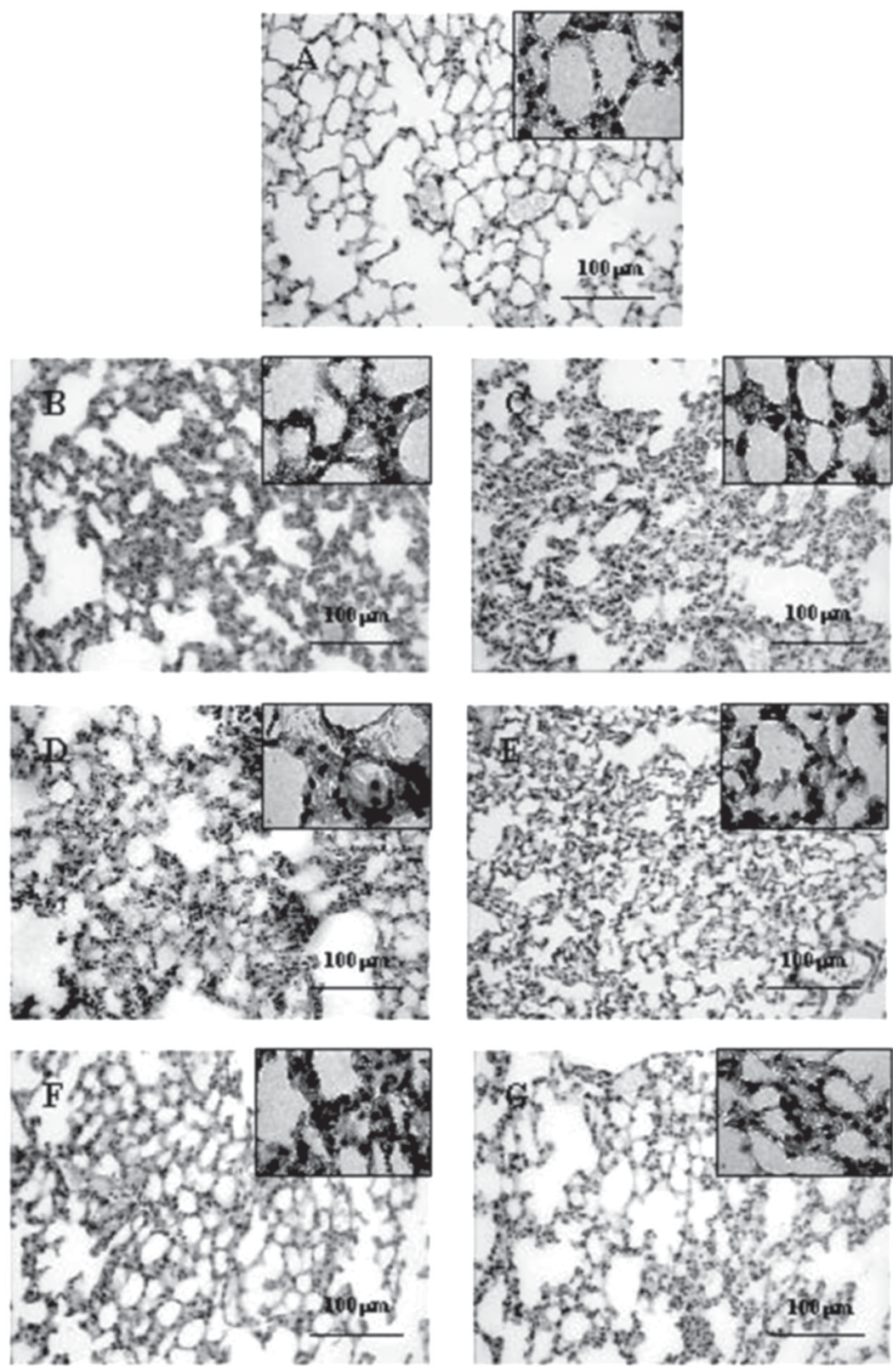

Figure 2. Photomicrographs of lung parenchyma stained with hematoxylin-eosin. $A$, Control group; $B, C, D, E, F$, and $G$, adult mice sacrificed at 2 and $8 \mathrm{~h}$ and at $1,2,3$, and 4 days after the injection of cyanobacteria extract, respectively. Photographs were taken at an original magnification of 200X. As shown in the insets (1000X) polymorphonuclear cells were the predominant cell type in this process. ment of inflammatory cells that remained stable until day 4, starting earlier in young animals. There was $100 \%$ survival until the end of the experiment.

Ito et al. (14) administered a similar sublethal dose of MCYST-LR intratracheally to mice and, using an immunostaining method, observed the presence of this toxin in the lungs until $7 \mathrm{~h}$ after injection. After this time, the tissue no longer showed any staining. They also detected a few stained macrophages in the lung and no lesion until the end of the experiment, 2 weeks later. Our results showed that cyanobacterial extracts containing microcystins lead to a rapid inflammatory response in the lung, which continued until the fourth and last day of the experiment. In addition, we observed alveolar collapse that also started rapidly and reached a maximum level earlier in young animals (Figure 1).

According to Naseem et al. (19), MCYSTLR can stimulate alveolar macrophages to produce inflammatory mediators. Nakano et al. (20) observed that TNF- $\alpha$ production by cultured macrophages from mouse peritoneal exudates is stimulated by purified microcystins and toxic and non-toxic extracts of $M$. aeruginosa (a non-lipopolysaccharide producer). They also observed that the toxic extract was more effective than purified microcystins. Therefore, it is important to consider that other cyanobacterial secondary metabolites present in the extract may induce inflammatory responses in lung or act synergistically with microcystins to promote inflammation.

We cannot rule out the presence of bacteria in the extract, which might contribute to those inflammatory effects. However, bacterial contamination of the M. aeruginosa culture was found to be very low and therefore negligible in the final volume of $M$. aeruginosa after the concentration process.

In the present study, these toxins and/or other cyanobacterial compounds may have caused the effects described above by reach- 
ing the lung through the blood stream after ip injection. Therefore, intravenous exposure to microcystins can represent a risk to the lungs in addition to the known targets, i.e., liver and kidney. Thus, whenever human health depends on the quality of water for direct consumption and recreational or medical use, such as dialysis treatment, the increase of cyanobacterial blooms producing microcystins in the water supplies ought to be carefully considered.

\section{References}

1. Carmichael WW (1994). The toxins of cyanobacteria. Scientific American, 270: 78-86.

2. Chorus I \& Bartram J (1999). Toxic Cyanobacteria in Water - A Guide to Their Public Health Consequences, Monitoring and Management. E \& FN Spon, London, UK.

3. Falconer I \& Humpage A (1996). Tumour promotion by cyanobacterial toxins. Phycologia, 35: 74-79.

4. Naseem SM, Hines HB \& Creasia DA (1990). Inhibition of microcystin-induced release of cyclooxygenase products from rat hepatocytes by anti-inflammatory steroids. Proceedings of the Society for Experimental Biology and Medicine, 195: 345-349.

5. Falconer IR, Beresford AM \& Runnegar MTC (1983). Evidence of liver damage by toxin from a bloom of the blue-green algae, Microcystis aeruginosa. Medical Journal of Australia, 1: 511-514.

6. Teixeira MdaG, Costa MdaC, Carvalho VLP, Pereira MS \& Hage E (1993). Gastroenteritis epidemic in the area of the Itaparica dam, Bahia, Brazil. Bulletin of the Pan American Health Organization, 27: 244-253.

7. Jochimsen EM, Carmichael WW, An J et al. (1998). Liver failure and death after exposure to microcystins at a haemodialysis center in Brazil. New England Journal of Medicine, 33: 873-878.

8. Carmichael WW, Azevedo SMFO, An J, Molica RJR, Jochimsen EM, Lau S, Rinehart KL, Shaw GR \& Eaglesham GK (2001). Human fatalities from cyanobacteria: chemical and biological evidence for cyanotoxins. Environmental Health Perspectives, 109: 663-668.

9. Azevedo SMFO, Carmichael WW, Jochimsen EM, Rinehart KL, Lau S, Shaw GR \& Eaglesham GK (2002). Human intoxication by microcystins during renal dialysis treatment in Caruaru - Brazil. Toxicology, 181: 441-446.

10. Fitzgeorge RB, Clark SA \& Kelvin CW (1994). Routes of intoxication. In: Codd GA, Jeffries TM, Kelvin CW \& Potter E (Editors), Detection Methods for Cyanobacterial (Blue-Green Algae) Toxins. The Royal Society of Chemistry, Cambridge, UK.
11. Turner PC, Gammie AJ, Hollinrake K \& Codd GA (1990). Pneumonia associated with cyanobacteria. British Medical Journal, 300: 14001441.

12. Slatkin DN, Stoner RD, Adams WH, Kycia JH \& Siegelman HW (1983). Atypical pulmonary thrombosis caused by a toxic cyanobacterial peptide. Science, 220: 1383-1385.

13. Ito $E$, Kondo F \& Harada K-I (2000). First report on the distribution of orally administered microcystin-LR in mouse tissue using an immunostaining method. Toxicon, 38: 37-48.

14. Ito $E$, Kondo F \& Harada K-I (2001). Intratracheal administration of microcystin-LR, and its distribution. Toxicon, 39: 265-271.

15. Ferrão-Filho AS \& Azevedo SMFO (2002). Effects of unicellular and colonial forms of toxic Microcystis aeruginosa from laboratory cultures and natural populations on tropical cladocerans. Aquatic Ecology, 37: 23-35.

16. Azevedo SMFO, Evans WR, Carmichael WW \& Namikoshi M (1994). First report of microcystins from a Brazilian isolate of the cyanobacterium Microcystis aeruginosa. Journal of Applied Phycology, 6: 261-265.

17. Nagase T, Lei M, Robatto FM, Eidelman DH \& Ludwig MS (1992). Tissue viscance during induced constriction in rabbit lung: morphological-physiological correlation. Journal of Applied Physiology, 73: 1900-1907.

18. Weibel ER (1990). Morphometry: stereological theory and practical methods. In: Gil J (Editor), Models of Lung Disease - Microscopy and Structural Methods. Marcel Dekker, New York.

19. Naseem SM, Hines HB \& Creasia DA (1989). Effect of toxins on arachidonic acid metabolism in rat cultured pulmonary alveolar macrophages. Biochemistry International, 19: 583-592.

20. Nakano Y, Shirai M, Mori N \& Nakano M (1991). Neutralization of microcystin shock in mice by tumor necrosis factor alpha antiserum. Applied and Environmental Microbiology, 57: 327-330. 